\title{
Challenges of Integrating Sustainability into Supply Chains of Small and Medium Scale Firms
}

\author{
Edward S. Fekpe and Yvonne Y. A. Delaporte
}

\begin{abstract}
This paper examines the challenges of integrating sustainability into supply chains of small and medium size manufacturing enterprises (SMEs) in a developing country, Ghana. Lack of integration among supply chain partners, lack of commitment on the part of the suppliers limited access to capital, limited resources, and high cost of sustainability implementation are identified as some of the challenges facing SMEs. Education, effective collaboration and communication among supply chain partners are considered key activities that could enhance sustainability integration.
\end{abstract}

Keywords - sustainable supply chain, integration, challenges, small and medium size enterprises, developing economy.

\section{Introduction}

The objective of supply chain sustainability is to create, protect and grow long term environmental, social and economic value for all stakeholders involved in bringing product and services to market (UNGC, 2010). Benefits of sustainable supply chain include achieving higher economic performance, optimizing resources and processes, cost savings, increased productivity, and above all as a driver of competitive advantage.

Small and medium size enterprises (SMEs) are the drivers of many developing economies even though some of them are hardly noticed. Undoubtedly, SMEs have contributed immensely to income, employment generation, and ultimately economic growth of many countries and are perceived as important actors in the drive for sustainability. For example, SMEs in Ghana have been noted to provide about 85 per cent of manufacturing employment and contribute about 70 per cent to Ghana's Gross Domestic Product (GDP). Increasing demands from various stakeholder groups and consumers compelled most companies to start looking at their supply chain to enhance their overall sustainability profile.

The survival of SMEs in a competitive market depends on their ability to implement sustainable supply chain practices. Noting that some of the partners (e.g., suppliers) in the supply chains of SMEs in the manufacturing industry are located in foreign countries, could be a challenge to integrating sustainability into their supply chains.

The objective of this paper is to examine the challenges of integrating sustainability into supply chains of new and

Ghana Institute of Management and Public Administration Accra, Ghana expanding manufacturing SMEs in a developing country like Ghana. The findings of this research are expected to contribute to knowledge on integrating the elements of sustainability into supply chains of local manufacturing SMEs with peculiar supply chain design and operational characteristics.

\section{Literature Review}

Theyel (2001) defined sustainable supply chain management (SSCM) as the strategic, transparent integration and achievement of an organization's social, environmental and economic goals in the systemic coordination of key interorganizational business process for providing the long term economic performance of the individual company and its supply chain. The importance of supply chain sustainability represents and comprehends the extension of economic, social, and environmental i.e., the triple bottomline (TBL) which has strongly grown in the last decades (Elkington 1998). Carter and Rogers (2008) noted that integration of the three legs of sustainability into the supply chain is a key issue of managerial practice and academic research (Figure 1 depicts the TBL concept.

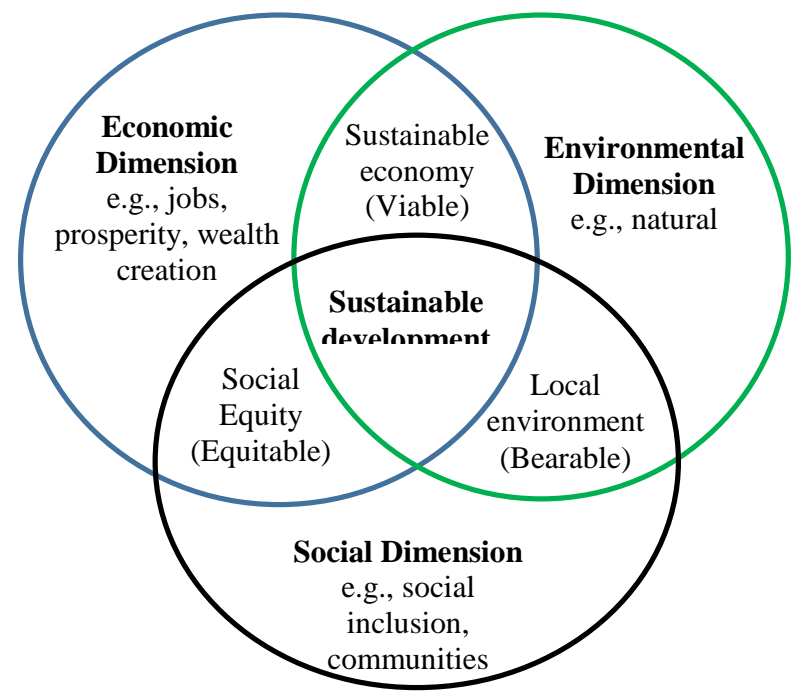

Figure 1. Triple Bottomline Concept

In a study of SMEs and sustainability initiatives, Schaper (2002) stated that there is great value for large and small businesses alike to invest in sustainability. SMEs are a means of innovation and change within the business sector and form an important support to large businesses with which they coexist. Although usually not given a great deal of attention, 
Proc. of the Fourth International Conference on Advances in Social Science, Management and Human Behaviour - SMHB 2016. Copyright (c) Institute of Research Engineers and Doctors. All rights reserved. ISBN: 978-1-63248-116-0 doi: 10.15224/ 978-1-63248-116-0-43

SMEs play a key role in the sustainability debate. However, studies have found that most SMEs tend to be somewhat reactive to environmental issues, and limited to small-scale, ad-hoc changes in business activities. This is also highlighted in Revell, Stokes, and Chen (2010), who stated that SMEs lag behind larger businesses in integrating environmental management into corporate strategies.

Porter and Kramer (2011) suggest that firms consider the principle of shared value in incorporating sustainability into their supply chains. Shared value involves creating economic value in a way that creates value for society by addressing its needs and challenges. Rao (2007) showed that business entities must address SSCM to TBL of economics, social and environmental components to maintain the performance of the firms. Carter and Rogers (2008) noted that firms that strategically undertake SSCM achieve higher economic performance than firms that pursue only one or two of the three components of the triple bottom line.

Integrating sustainable practices into the supply chain systems is a business necessity to save the environment. SSCM is considered a business challenge for organizations to implement. There are many obstacles to its implementation. Yet, there are other factors that act as drivers for SSCM implementation. Results from previous studies highlight major drivers and barriers that medium sized business face when making sustainable and ecological progress an actuality in their current supply chain operations. Wollmuth and Velislava (2014) observed that incorporating sustainability into a company's supply chain is complex but the failure to act may be the biggest risk of all.

According to Hutchins and Sutherland (2008) and Kleindofer et al., (2005) supply chain sustainability dimensions are interdependent, and even though the concept is well established, businesses still struggle to implement SC sustainable practices adequately. Several approaches for integrating sustainability into supply chains are available in the literature. Examples include: Wollmuth and Velislava (2014) suggested a six step process; Hanifan et al., (2012) suggested three specific ways for integrating sustainability into supply chains; and Cetinkaya et al (2011) described a sixstep iterative approach that defines the sustainable supply chain road map. A recent study, Reefke et al., (2010), developed a maturity model for integrating sustainability into supply chains. The degree of complexity and the steps involved are not necessarily similar and each approach may have its merits and demerits. There is no widely accepted process or procedure for integrating sustainability into supply chains.

There is evidence to suggest the large multi-national companies operating in Ghana have demonstrated commitment to integrate sustainability into their supply chains. For example, Nestlé Ghana's cocoa plan enables it to work closely with its cocoa suppliers to ensure that supply chain operations are sustainable. This program focuses on 3 main pillars - (i) enabling farmers to run profitable farms through training; (ii) improving social conditions by eliminating child labor and focusing on women; (iii) sourcing sustainable good quality cocoa by increasing transparency in the supply chain and respecting the environment (Nestlé, n.d.). Also, in 2012 Unilever Ghana obtained 100 percent of its palm oil requirements from sustainable sources. Similarly, in 2013, 48 percent of the Unilever Ghana's agricultural raw materials were sustainably sourced (Unilever, n.d.).

Evidence of sustainable supply chain for SME's on the other hand is limited. Integrating sustainability in the supply chains of SMEs is critical because without it, there is the risk of loss of market share, as well as time and cost of re-entering a market.

\section{Methodology and Conceptual Framework}

According to Baldwin, (2009), companies are increasingly challenged to balance business performance and economic gains with environmental and social issues. Therefore, it has become necessary to help decision-makers select from among various sustainable improvement. Chaabane et al., (2012) stated that the TBL concept evokes the need for an integrated approach that links supply chain design decisions to all three pillars (economic, environmental and social) of sustainability. With this background, the conceptual framework for this study can be represented by Figure 2. This framework is grounded on the systems theory where all levels of interaction among the three legs collectively determine the level of integration of sustainability and hence the performance of the supply chain.

The conceptual framework consists of four constructs: the first construct relates to 'ECONOMIC'; the second construct relates to 'ENVIRONMENTAL', and the third construct relates to 'SOCIAL'. These elements together define the TBL concept of sustainable supply chain. The interactions determine the level of integration which is the fourth construct (INTEGRATION). Conceptually the degree or level of integration then determines performance of the firm. However there are barriers or challenges to attain complete and successful integration (Figure 2).

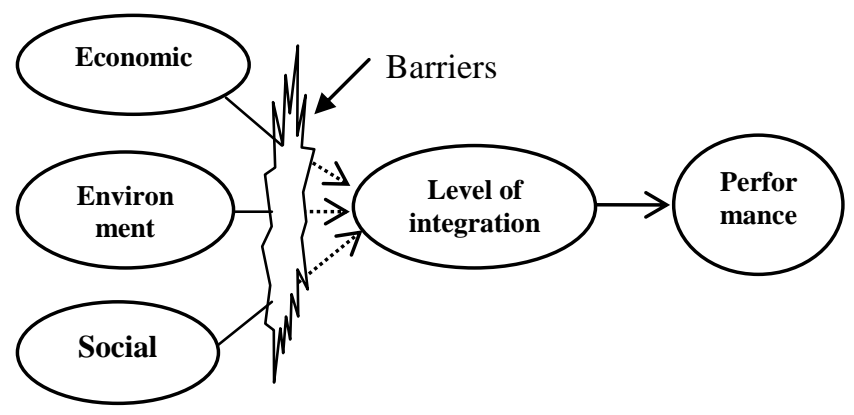

Figure 2. Conceptual Frameworkl

A multiple case study approach was used where purposive sampling was used in selecting the cases. This sampling approach is considered appropriate for this study because the population of SMEs is large, cutting across all industries and geographically dispersed throughout the country. Thus a statistically representative sample will be large. The case study approach is considered appropriate for this study because it 
Proc. of the Fourth International Conference on Advances in Social Science, Management and Human Behaviour - SMHB 2016. Copyright (c) Institute of Research Engineers and Doctors. All rights reserved. ISBN: 978-1-63248-116-0 doi: 10.15224/ 978-1-63248-116-0-43

focuses on the phenomenon of sustainability integration within the context of supply chain management.

A total of twenty (20) Ghanaian owned manufacturing SMEs operating in the capital city and its immediate environs were selected to represent a cross-section of SMEs in Ghana. Industries of particular interest include (i) cosmetics (shower gels, soaps and body lotions) (10 firms), (ii) furniture (7 firms), and (iii) fruit juice (3 firms). The sample is expected to provide insights of the characteristics, challenges, and issues typical of SMEs. Data was collected through interviews with structured guides. For the purposes of the study a five point Likert scale ranging from (1) strongly disagree; (2) disagree; (3) neutral i.e., neither agree nor disagree; (4) agree; to (5) strongly agree with statements for each of the constructs in the conceptual framework. Data gathered were analyzed with the SPSS software. First descriptive statistics of the responses were analyzed followed by correlations between each of the three legs of sustainability and integration were tested. Based on the results of correlation analysis the factors contributing to the poor correlations are discussed.

\section{Iv. Discussion of Findings}

This section discusses the findings from the data analysis. The discussion first presents a situation analysis that describes the current status of integration of sustainability into supply chains of the sample of manufacturing SMEs included in this study. This is followed by a discussion of the characteristics and challenges encountered by the SMEs.

\section{A. Situation Analysis}

Descriptive statistics analysis of the data gathered were conducted for each of the three industries individually and then collectively. Comparison of the results is displayed in Figure 3. Clearly, all firms appear to appreciate the concept of sustainable supply chains as the values are above the neutral line (i.e., 3) even though the level of appreciation for the three legs vary by industry.

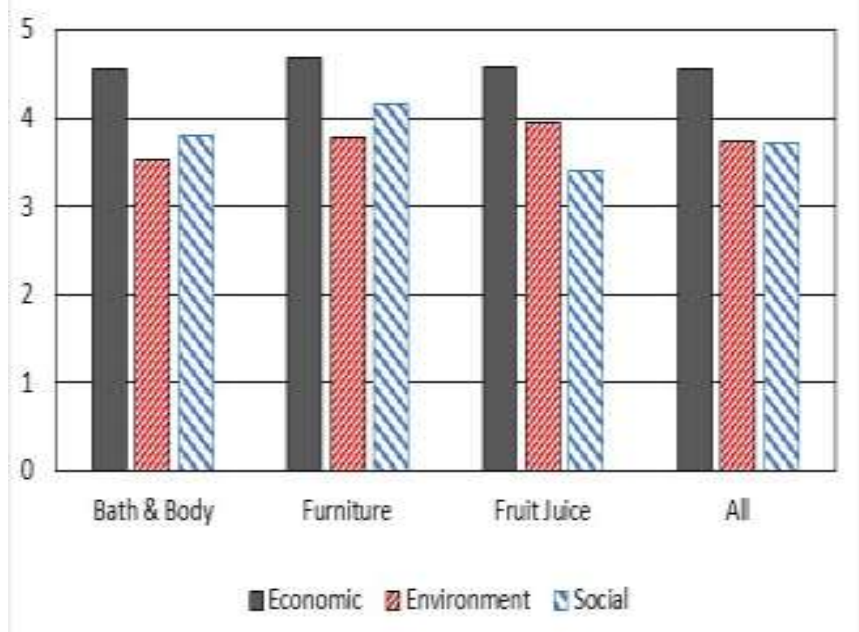

Figure 3. Comparison of Integration by Industry
The results also indicate that for the industries sampled, the economic leg of sustainability appears to be more integrated compared to the environment and social legs. This is expected because all businesses are set up with the primary objective to be economically viable and therefore one would expect more focus on the economic element of sustainability. Contrary to expectations it is noted that implementation of environmental aspects are generally lower than the social aspects. This is unexpected because environmental impacts are more visible (or noticeable) and are more regulated than the social aspects.

The fruit juice production firms however appear to have integrated the environmental aspects into their processes. This may not be a true reflection of practices in this industry as whole given the very small sample size used in this study. Nonetheless, this finding highlights the need for all industries to make efforts to integrate the environmental sustainability into their supply chains.

Results of pairwise correlation analysis also indicate that the three elements individually and collectively are positively correlated with integration (see Table 1). However, the degree or strength of the correlation indicated by the coefficients vary form 0.44 for the economic aspects to 0.55 for the environment aspects. It important to note that the coefficient for the collective contribution of the three sustainability legs is the highest (i.e., 0.59).

TABLE I. SUMMARY OF PAIRWISE CORRELATION

\begin{tabular}{|c|l|c|l|}
\hline Element & Coefficient & $\mathbf{P}>|\mathbf{t}|$ & \multicolumn{1}{|c|}{ Remarks } \\
\hline Economic & 0.4442 & 0.0000 & Signficant at 95\% \\
\hline Environment & 0.5549 & 0.0000 & Signficant at 95\% \\
\hline Social & 0.4929 & 0.0000 & Signficant at 95\% \\
\hline All three & 0.5887 & 0.0000 & Signficant at 95\% \\
\hline
\end{tabular}

It is noted that the correlations are significant at the $95 \%$ significance level. These findings support the systems theory that interactions and interdependencies among the three legs that define sustainability, collectively determine the degree of integration. These values also suggest that stronger correlations could be achieved.

\section{в. Challenges of Sustainability Integration}

SMEs in Ghana are engaged in many different industries including but are not limited to fruit juice; furniture; shoes; handicrafts; toilet soap; cosmetics; confectionary; agro-based; retail; purified water; and food products. To help understand the supply chains of SMEs, it is important to highlight some common characteristics that define their supply chains and operations. These characteristics define the challenges they encounter in integrating sustainability concepts into their supply chains. 
Proc. of the Fourth International Conference on Advances in Social Science, Management and Human Behaviour - SMHB 2016. Copyright (c) Institute of Research Engineers and Doctors. All rights reserved. ISBN: 978-1-63248-116-0 doi: 10.15224/ 978-1-63248-116-0-43

- SMEs typically operate with direct supply chains where the suppliers, the focal manufacturing company, and the customer are partners in the supply chain. Suppliers may have their own (second-tier) suppliers. In other words, the operations are limited to the immediate partners (upstream and downstream) in the supply chain. Any attempts to integrate sustainability into the operations for the focus firm does not necessarily extend to these partners.

- The number of raw materials required are relatively few. Therefore the number of suppliers to manage are equally few. Conceivably, collaboration may be easier to achieve. On the contrary however, the partners in the supply chain and not integrated. Furthermore, the SMEs interviewed have not invested time and money in developing their suppliers by partnering and forming alliances with them. Therefore, lack of integrated supply chains makes it difficult to introduce sustainable elements across the entire supply chains.

- SMEs compete with larger companies and they have little control over supplier practices. Ideally, SMEs engaged in fresh fruit juice production, for example, should work closely with the various fruit farmers to ensure that they use only the approved agrochemicals, that wastes are properly disposed of without polluting soil and water bodies; that safety and health practices are adhered to and that farm workers' rights are respected and protected. This is however not the case because too many customers (manufacturers) are served by few suppliers of the same inputs. Lack of commitment on the part of the suppliers is a challenge.

- SMEs that rely on imported suppliers have little or no control over the responsibility for the consequences of non-sustainable practices of their suppliers. While some of these local SMEs may attempt to integrate sustainability into their operations, they cannot ensure that all partners of the supply chains will also do so.

- Access to capital is a major restricting factor for SMEs. With limited access to capital, integration of sustainability is not top priority. However, these firms recognize that to remain competitive, they have to implement sustainability concepts into their operations.

- Production cost for local SMEs is high due to high cost of capital, interest rate, and labor cost compared to that of competing imported products that are readily available on the local market. Integration of sustainability into supply chains is an extra cost that SMEs may not be able afford.

\section{Commentary}

Several challenges for integrating sustainability into supply chains of manufacturing SMEs have been identified. Overcoming these challenges is seen as an enormous task.
While the SME's acknowledge the concept of supply chain sustainability and recognize the benefits, implementation challenges should be addressed to some reasonable extents not only to ensure they are sustainable and remain competitive, but also to improve their performances in general.

Based on information in the literature, elements of successful sustainability implementation require understanding of the supply chain and its characteristics; information sharing and working closely with the suppliers and other partners in the supply chain. Collaboration with partners in the supply chain and supplier continuity are considered important elements for successful sustainability integration.

The critical first step is recognition and appreciation of the concept and the benefits of sustainable supply chains. Education and communication are considered key for better decision making regarding performance of the supply chains.

\section{v. Conclusions}

While SMEs acknowledge and embrace the concept of sustainability several challenges have been identified that prohibit integration into supply chains of manufacturing SMEs. Lack of integration among partners in the supply chains, lack of commitment on the part of the suppliers, limited access to capital, limited resources, and high cost of sustainability implementation are some of the challenges facing SMEs in developing countries. SMEs that rely on imported suppliers have little control over the responsibility for consequences on non-sustainable practices of their suppliers.

Education, effective collaboration and communication among supply chain partners for SMEs are activities that could enhance sustainability integration.

\section{References}

[1] Baldwin C.J., (20090. Sustainability in the food industry. IFT Press, Wiley Blackwell, USA

[2] Carter, C. R. and D. S. Rogers. 2008. A framework of sustainable supply chain management: Moving toward new theory. International Journal of Physical Distribution and Logistics Management 38 (5): 360-387.

[3] Cetinkaya, B., Cuthbertson, R., Ewer, G., Klass-Wissing, T, Pitotrowicz, W., and Tyssen, C. (2011). Sustainable supply chain management: practical ideas for mowing towards best practice. Retrieved on Fed. 16, 2015 from http://www.springer.com/978-3-642-12022-0

[4] Chaabane' A., Ramudhin, A. and Paquet, M. (2012). Design of sustainable supply chains under the emission trading scheme. International Journal of Production Economics, Vol 135, Issue 1, pp. $37-$ 49.

[5] Elkington, J. 1998. Cannibals with Forks: The Triple Bottom Line of 21st Century. New Society Publishers, Gabriola Island, British Columbia

[6] eServices (n.d.) Empowering SMEs in Ghana for Global Competiveness. $\begin{array}{llll}\text { Retrieved October } & 21, & & \\ & & & \end{array}$ http://www.eservices.gov.gh/Pages/Empowering-SMEs-in-Ghana-forGlobal-Competitiveness.aspx.

[7] Retrieved Sep. 24, 2016 from http://www.accenture.com/usen/outlook/Pages/outlook-journal-2012-why-sustainable-supply-chainis-good-business.aspx 
Proc. of the Fourth International Conference on Advances in Social Science, Management and Human Behaviour - SMHB 2016.

Copyright (c) Institute of Research Engineers and Doctors. All rights reserved. ISBN: 978-1-63248-116-0 doi: 10.15224/ 978-1-63248-116-0-43

[8] Hutchins, M. J and Sutherland, J. W. (2008) An Exploration of Measures of Social Sustainability and their Application to Supply Chain Decisions. Journal of Cleaner Production 16(15):1688-1698

[9] Kleindorfer, P. R., K. Singhal, and L. N. V. Wassenhove. 2005. Sustainable operations management. Production and Operations Management 14 (4): 482-492.

[10] Nestlé. (n.d.). .Nestlé Ghana commits to a sustainable cocoa supply chain through the Nestlé cocoa plan. Retrieved Sep 10, 2016 from http://www.nestlecocoaplan.com/nestle-ghana-commits-to-a-sustainablecocoa-supply-chain-through-the-nestle-cocoa-plan/

[11] Porter, M. E., and Kramer, M. R. (2011). Creating shared value: how to reinvent capitalism- and unleash a wave of innovation and growth. Harvard Business Review, January-February 2011

[12] Rao, N.H. (2007). A Framework for Implementing Information and Communication Technologies in Agricultural Development in India. Technological Forecasting and Social Change. Vol. 74, No. 4, pp. 491 -518 .

[13] Reefke, H., Sundaram, D. and Ahmed, M.D. (2010). Maturity progression model for sustainable supply chains. Advanced Manufacturing and Sustainable Logistics, 46, 308-318.

[14] Revell, A., D. Stokes, and H. Chen. 2010. Small businesses and the environment: Turning over a new leaf? Business Strategy and the Environment 19 (5): 273-288.

[15] Schaper, M. 2002. Small forms and environmental management. International Small Business Journal 20 (3).

[16] Theyel, G. (2001). Customer and Supplier Relations for Environmental Performance, Greener Management International, Autumn 2001, Vol. 35, pp. 61-69.

[17] Unilever (n.d.) Sustainable Sourcing. Retrieved March 4, 201 form http://www.unileverghana.com/sustainable-living-2014/sustainablesourcing/index.aspx..

[18] United Nations Global Compact (2010). Supply Chain Sustainability: A Practical Guide for Continuous Improvement. United Nations Global Compact Office. Retrieved March 10, 2015 from Retrieved from http://www.bsr.org/reports/BSR_UNGC_SupplyChainReport.pdf

[19] Wollmuth, J. and Velislava, I. (2014) 6 steps for a more sustainable supply chain. Retrieved March 10, 2016 from http://www.greenbiz.com/blog/2014/01/24/6-steps-more-sustainablesupply-chain.

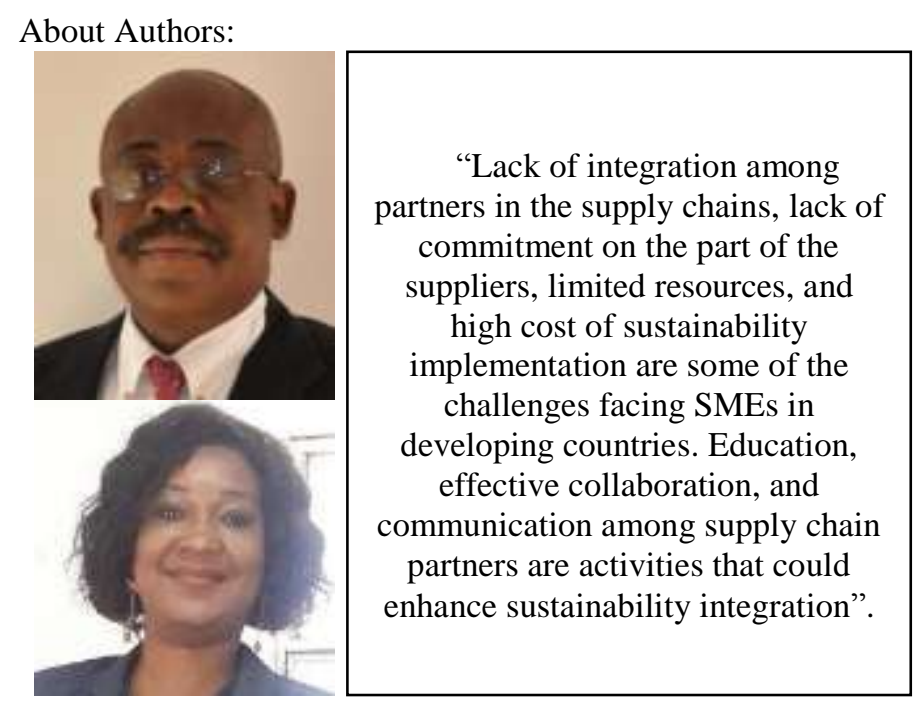

